\title{
La búsqueda de HPV es de ayuda diagnóstica ante la atipía de células escamosas de significado indeterminado
}

Identifying women with cervical neoplasia. Using human papillomavirus DNA testing for equivocal papanicolaou results. Manos M; Kinney W; Hurley L, Sherman M et al. JAMA 1999; 281: 1605-1610.

\section{Objetivo}

Determinar si en las mujeres cuyo papanicolaou (PAP) fue clasificado como: "atipía de células escamosas de significado indeterminado" (ACESI o en inglés ASCUS), la detección de infección por papiloma virus humano (HPV) en el material residual de la toma del PAP y la búsqueda de lesión colposcópica tiene mayor sensibilidad para identificar pacientes con lesión intraepitelial de alto grado (SIL-AG) que la repetición del PAP.

\section{Diseño}

Estudio de corte transversal de una cohorte de mujeres que concurrieron a un examen ginecológico de rutina.

\section{Lugar}

Carolina del Norte, EE.UU.

\section{Pacientes}

Entre octubre de 1995 y junio de 1996 participaron 995 mujeres de 15 a 78 años (edad media: 37 ). Se excluyeron aquellas que estuviesen embarazadas o se hubiesen tratado por neoplasia cervical en los seis meses previos.

\section{Descripción de las pruebas y del test de referencia}

En un lapso de 12 a 240 días se les realizó a todas las pacientes PAP y colposcopía. En quienes se logró identificar visualmente la lesión se realizó biopsia y en quienes no, curetaje endocervical.

Con el material de la toma del PAP se testeó infección por HPV para los tipos de alto riesgo $(16,18,31,33,35,39,45,51,56$ y 58).

\section{Medición de resultados}

Se evaluó la histología cervical, la citología del PAP repetido, el resultado del test para HPV y la sensibilidad de la detección de infección por HPV para identificar pacientes con SIL-AG.

\section{Resultados principales}

De las 46.009 mujeres rastreadas, 995 tuvieron diagnóstico citológico de ACESI y aceptaron participar del estudio. En ellas el PAP fue de apariencia reactiva en $451(45,3 \%)$, de apariencia neoplásica en 273 $(27,4 \%)$, y de apariencia indeterminada en $271(27.2 \%)$.

La mayoría de las pacientes $(79,1 \%)$ tuvo histología normal. Se identificó un caso de cáncer invasivo y 64 casos de SIL-AG. Se detectó infección por HPV en 384 mujeres (39,5\%). La sensibilidad de testear HPV para identificar pacientes con ACESI y con probable SIL-AG o cáncer subyacente fue de $89,2 \%$ (IC $95 \%: 78,4$ a $95,2 \%$ ) y la especificidad, de $64,1 \%$ (IC95\%: 60,9 a 67,2\%). Por otro lado, la sensibilidad de la repetición del PAP para la detección de SIL-AG fue de 76,2\% (IC95\%: 63,5 a 85,7\%). Se calcularon los valores predictivos * positivo (VPP) y negativo (VPN) para cada estrategia, a partir de los casos referidos para colposcopía (ver tabla).

\begin{tabular}{lcccc}
\hline Estrategia & $\begin{array}{l}\text { Prevalencia } \\
\text { de lesión } \\
(\%, \text { IC 95\%) }\end{array}$ & $\begin{array}{c}\text { Sensibilidad } \\
\text { para SIL-AG } \\
(\%, \text { IC 95\%) }\end{array}$ & $\begin{array}{l}\text { VPP para } \\
\text { para SIL-AG } \\
(\%, \text { IC 95\%) }\end{array}$ & $\begin{array}{c}\text { VPN para } \\
\text { para SIL-AG } \\
(\%, \text { IC 95\%) }\end{array}$ \\
\hline $\begin{array}{l}\text { Basado en } \\
\text { resultado } \\
\text { de HPV }\end{array}$ & $\begin{array}{c}39,5 \\
(36,4-42,7)\end{array}$ & $\begin{array}{c}89,2 \\
(78,4-95,2)\end{array}$ & $\begin{array}{c}15,1 \\
(11,7-19,2)\end{array}$ & $\begin{array}{c}98,8 \\
(97,4-99,5)\end{array}$ \\
\hline $\begin{array}{l}\text { Basado en } \\
\text { repetición } \\
\text { delPAP }\end{array}$ & $\begin{array}{l}38,9 \\
(35,8-42,1)\end{array}$ & $\begin{array}{c}76,2 \\
(63,5-85,7)\end{array}$ & $\begin{array}{c}12,9 \\
(9,8-16,8)\end{array}$ & $\begin{array}{c}97,4 \\
(95,7-98,5)\end{array}$ \\
\hline
\end{tabular}

\section{Conclusiones}

Basados en los resultados de este estudio, la estrategia de detectar infección por HPV en las pacientes con resultados de PAP indeterminado (ACESI) aumenta la sensibilidad para identificar pacientes con lesiones de alto grado.

Fuente de financiamiento: Kaiser Permanente Innovations Program, Cytyc Corporation, Digene Corporation

\section{COMENTARIO}

En el taller del Instituto Nacional de Cáncer en Bethesda1, para el reporte de diagnósticos citológicos cervicovaginales en 1988, fue introducida la clasificación de células escamosas atípicas de significado indeterminado. Se define ACESI cuando las anomalías celulares son más severas que los cambios reactivos o inflamatorios pero no cumplen criterios de lesión escamosa intraepitelial.

Se han propuesto diferentes opciones para el manejo de pacientes con ACESI: seguirlas con papanicolaou, descartar la presencia de infecciones de transmisión sexual y en quienes persiste o en pacientes de alto riesgo, realizar colposcopía.

El testeo de infección por HPV para la identificación de pacientes con alto o bajo riesgo de desarrollar neoplasia cervical es un tema controvertido ${ }^{2}$. Esta controversia se debe a que la infección por HPV es también muy común en mujeres con PAP normal y a que su prevalencia no se conoce. No obstante, la detección de infección por un tipo de HPV de alto riesgo es sugestiva de lesión escamosa en quienes tienen PAP anormal. Por otro lado, si el HPV resulta ser de los tipos de bajo riesgo $(6,11,42,44)$ la probabilidad de que esta lesión progrese a cáncer sería baja. Para complicar más aún la cuestión agregamos que hay lesiones con tipos HPV aún no conocidos y también lesiones que no se

*Ver glosario asocian a infección por HPV.

Este estudio demuestra que la detección de infección por HPV aumenta la sensibilidad para identificar pacientes con SIL-AG. No obstante, cuando observamos los valores predictivos positivos, la diferencia que existe entre testear el y repetir el PAP es muy pequeña.

En conclusión, si bien por un lado no se conoce con certeza la prevalencia de infección por HPV, sí se ha demostrado que las pacientes con diagnóstico de ACESI tienen mayor riesgo de desarrollar lesiones escamosas. Por otro lado, los resultados obtenidos en esta población pueden no ser generalizables (en este estudio en particular no están detalladas las características de las pacientes, excepto la raza y edad). Considero que cuando se trata de decidir cual es la conducta más apropiada ante un resultado de PAP indeterminado uno debería pensar en función de las características (los factores de riesgo) que presenta la paciente en particular.

Los autores sostienen que la realización de coloscopía genera ansiedad en las pacientes, lo cual es discutible en nuestro medio, especialmente si se compara la preocupación que puede producir una colposcopía con la de identificar una enfermedad de transmisión sexual que se sabe que aumenta el riesgo de desarrollar cáncer.

\section{Dra. Vilda Discaciatti}

Unidad de Medicina Familiar y Preventiva. Hospital Italiano de Buenos Aires.

Referencias

1. Kurman RJ, Henson DE, Herbst AL, et al.; for The National Cancer Institute Workshop. Interim guidelines for management of abnormal cervical cytololgy. Jama 1994 (271): 1866-1869. 2. Ferris DG, Wright TC Jr, Litaker MS et al. Triage of women with ASCUS and LSIL on pap smear reports: Management by repeat pap smear, HPV DNA testing, or colposcopy. J Fam Pract 1998 (46): 125-34. 